\title{
A RESOLUÇÃO DE PROBLEMAS NA FORMAÇÃO CONTINUADA DE PROFESSORES DE MATEMÁTICA DA EDUCAÇÃO BÁSICA
}

\section{MALCUS CASSIANO KUHN}

Instituto Federal de Educação, Ciência e Tecnologia Sul-rio-grandense - Campus Lajeado.

E-mail:malcuskuhn@ifsul.edu.br

\section{ARNO BAYER}

Universidade Luterana do Brasil - ULBRA

E-mail: bayer@ulbra.br

\begin{abstract}
RESUMO
O artigo discute a resolução de problemas na formação continuada de professores de Matemática da Educação Básica, fundamentando-se em autores e documentos legais que abordam a formação continuada de professores e a resolução de problemas. Investiga-se a metodologia de resolução de problemas como recurso didático na construção do conhecimento matemático durante a formação continuada de 24 professores de Matemática em serviço. A formação possibilitou a pesquisa sobre a metodologia de resolução de problemas e o desenvolvimento de ações didáticas reflexivas, articulando-se teoria com prática na resolução de problemas, contribuindo para a ressignificação de conhecimentos matemáticos e da metodologia de resolução de problemas no fazer pedagógico de professores de escolas públicas.
\end{abstract}

PALAVRAS-ChAVE:

Resolução de problemas; Formação continuada; Professores de Matemática; Educação Básica.

THE PROBLEMS RESOLUTION IN THE CONTINUING FORMATION OF MATHEMATICS TEACHERS OF BASIC EDUCATION

\section{ABSTRACT}

The article discusses the problems resolution in the continuing formation of Mathematics teachers of the Basic Education. It investigates the problems resolution methodology as a didactic resource in the construction of the mathematical knowledge during the continuing formation of 24 Mathematics teachers in service. The continuing formation has enabled the research about the problems resolution methodology and the development of reflective didactic actions, linking up theory with practice in the problems resolution, contributing to the ressignification of mathematical knowledge and of the problems resolution methodology in the pedagogical practice of teachers from public schools.

\section{KEYWORDS:}

Problems resolution; Continuing formation; Mathematics teachers; Basic Education. 


\section{INTRODUÇÃO}

O tema formação de professores é complexo e exige atenção diante do momento de mudanças no qual nossa sociedade está inserida. A formação de professores começa a ser discutida em diversos âmbitos o que deve contribuir significativamente para a prática pedagógica. As lacunas na formação inicial e continuada dos educadores são evidentes e merecem atenção. De acordo com Kuhn e Bayer (2013), para uma melhor qualidade no ensino, além do conhecimento dos conteúdos de ensino, é necessário que o professor possua um conjunto de saberes abrangentes, didáticos e transversais, provenientes de sua formação contínua e de trocas com os colegas, construídos ao longo de sua experiência.

Felizmente as universidades, principais responsáveis pela formação de professores, estão reavaliando os processos de formação e buscando in loco, investigar os problemas na formação dos profissionais da educação. Eventos realizados em 2015 e 2016, relacionados à Educação Matemática também discutem a temática, como a XIV Conferência Interamericana de Educação Matemática - XIV CIAEM, o XII Encontro Gaúcho de Educação Matemática - XII EGEM, o III Congresso Ibero-americano de História da Educação Matemática - III CIHEM, o VI Seminário Internacional de Pesquisa em Educação Matemática - VI SIPEM e o XII Encontro Nacional de Educação Matemática - XII ENEM.

O presente artigo é um estudo qualitativo do projeto Resolução de Problemas Matemáticos na Formação Continuada de Professores da Educação Básica do Vale do Taquari, aprovado no Edital PROEX/IFSUI - № 07/2014. Um projeto que consistiu num processo educativo, social, científico e tecnológico, promovendo a interação entre um campus do Instituto Federal de Educação Ciência e Tecnologia Sul - rio - grandense IFSul e escolas públicas de Educação Básica, por meio de dois cursos de extensão para professores de Matemática, um voltado para os anos finais do Ensino Fundamental e 
o outro, para o Ensino Médio. O principal objetivo do projeto foi potencializar a metodologia de resolução de problemas como recurso didático na construção do conhecimento matemático durante a formação continuada de professores de Matemática em serviço.

Buscaram-se autores e documentos legais que abordam a formação continuada de professores e a resolução de problemas para dar suporte ao estudo da resolução de problemas na formação continuada de professores de Matemática da Educação Básica.

\section{A FormaÇÃo CONTINUAdA de PROFESSORES de MATEMÁtICA}

A importância da formação continuada de professores é discutida em documentos legais e por diversos autores, entre os quais se destacam: Candau (1996), Falsarella (2004), Faustino (2011), Ibernón (2002), Nóvoa (2002) e Perrenoud (2002). Estes e outros pesquisadores apontam a necessidade de atender às exigências da sociedade, que clama pelo ensino de qualidade e por práticas pedagógicas inovadoras que preparem os alunos para o verdadeiro exercício da cidadania. Os mesmos se preocupam em diagnosticar, descrever ou construir caminhos que superem as dificuldades apresentadas pelos sistemas de ensino ou mesmo pelos educadores em geral.

A escola está desempenhando vários e novos papeis na sociedade atual. Este vem sendo um campo de constante mutação, e o professor tem um papel central: é ele o responsável pela mudança de atitude e pensamento dos alunos. O professor precisa também estar preparado para os novos e crescentes desafios desta geração que nunca esteve tão em contato com tecnologias e fontes de acesso ao conhecimento, como hoje. 
A Resolução CNE/CP ${ }^{1}$ no 2 de 1을 de julho de 2015, que define as Diretrizes

Curriculares Nacionais para a formação inicial em nível superior (cursos de licenciatura, cursos de formação pedagógica para graduados e cursos de segunda licenciatura) e para a formação continuada, traz orientações sobre a formação continuada dos profissionais do magistério no capítulo VI:

Art. 16. A formação continuada compreende dimensões coletivas, organizacionais e profissionais, bem como o repensar do processo pedagógico, dos saberes e valores, e envolve atividades de extensão, grupos de estudos, reuniões pedagógicas, cursos, programas e ações para além da formação mínima exigida ao exercício do magistério na educação básica, tendo como principal finalidade a reflexão sobre a prática educacional e a busca de aperfeiçoamento técnico, pedagógico, ético e político do profissional docente.

Parágrafo único. A formação continuada decorre de uma concepção de desenvolvimento profissional dos profissionais do magistério que leva em conta:

I - os sistemas e as redes de ensino, o projeto pedagógico das instituições de educação básica, bem como os problemas e os desafios da escola e do contexto onde ela está inserida;

II - a necessidade de acompanhar a inovação e o desenvolvimento associados ao conhecimento, à ciência e à tecnologia;

III - o respeito ao protagonismo do professor e a um espaço tempo que the permita refletir criticamente e aperfeiçoar sua prática;

IV - o diálogo e a parceria com atores e instituições competentes, capazes de contribuir para alavancar novos patamares de qualidade ao complexo trabalho de gestão da sala de aula e da instituição educativa (BRASIL, 2015, p. 13-14).

Ainda de acordo com esta resolução, a formação continuada deve se dar pela oferta de atividades formativas diversas incluindo atividades e cursos de atualização e extensão, cursos de aperfeiçoamento, cursos de especialização, cursos de mestrado e doutorado que agreguem novos saberes e práticas, articulados às políticas e gestão da educação, à área de atuação do profissional e às instituições de educação básica, em suas diferentes etapas e modalidades. A formação continuada deve se efetivar por meio de projeto formativo que tenha por eixo a reflexão crítica sobre as práticas e o exercício profissional e a construção identitária do profissional do magistério. Nóvoa 
(2002) defende o (re)encontro de espaços de interação entre as dimensões pessoais e

profissionais, permitindo aos professores apropriar-se dos seus processos de formação e dar-Ihes um sentido no quadro das suas histórias de vida.

Para Faustino (2011), o conhecimento dos modelos de formação continuada pode subsidiar a elaboração de propostas de formação que venham a contribuir na construção dos saberes docentes. Neste sentido, a autora ressalta que:

A eficácia das ações de formação continuada está relacionada com processos formativos amparados em modelos que se pautam na reflexão sobre a prática, na discussão do coletivo, na participação voluntária dentro da própria escola, que favorece a troca de experiências, que provoca reflexões e mobiliza saberes, na busca do saber-fazer, na resolução dos problemas e das dificuldades da prática docente, na busca pela autonomia profissional e na articulação entre teoria e prática (FAUSTINO, 2011, p. 26).

Na tentativa de romper com a dicotomia entre "o que ensinar" e "como ensinar", Shulman (1986 apud FAUSTINO, 2011) propõe três categorias do conhecimento do professor, quando se refere ao conhecimento da disciplina a ser ensinada: conhecimento disciplinar (ou do conteúdo), conhecimento pedagógico e conhecimento curricular. Essas três categorias englobam um conjunto de sete conhecimentos de base para o ensino:

Conhecimento do conteúdo; conhecimento pedagógico geral (princípios gerais e estratégicos para a gestão da sala de aula, fundamentais para ensinar o conteúdo); conhecimento curricular (conhecimento do professor para compreensão da matéria e dos programas que servem como ferramentas para os mesmos); conhecimento pedagógico do conteúdo (combinação especial entre o conteúdo e a pedagogia); conhecimento dos alunos e suas características; conhecimento dos contextos educacionais (desde o trabalho da sala de aula, de governança e financiamento dos espaços escolares, até o caráter de comunidades e culturas); conhecimento dos fins da educação (propósitos e valores e seus fundamentos filosóficos e históricos) (SHULMAN, 1986, apud FAUSTINO, 2011, p. 29).

Conforme Faustino (2011, p. 29), "o conhecimento disciplinar se refere tanto à compreensão do conteúdo quanto a sua organização, ou seja, o professor deve compreender a disciplina que vai ensinar e, ao mesmo tempo, fazer conexões com as demais áreas de conhecimento". 
Para Shulman (1986 apud FAUSTINO, 2011, p. 30), "o conhecimento pedagógico é um conjunto de conhecimentos e capacidades características do professor e envolve as diversas formas de abordagem de um conteúdo para torná-lo mais compreensivo".

Segundo Faustino (2011, p. 30), "o conhecimento curricular envolve um conjunto de programas elaborados para o ensino de assuntos específicos de um determinado nível escolar, diferentes materiais, bem como a diversidade de instrumentos de trabalho relacionados a tais programas".

Candau (1996) destaca que na formação continuada o lócus da formação a ser privilegiado é a própria escola e que todo processo de formação continuada tem que ter como referência fundamental o saber docente. Acrescenta ainda que, para adequado desenvolvimento da formação continuada, é necessário ter presentes as diferentes etapas do desenvolvimento profissional do magistério, haja vista que, as necessidades e os problemas dos professores em fase inicial, daqueles que possuem mais tempo de experiência e dos que estão no final de carreira são diferentes.

Estudos têm demonstrado que no dia a dia da escola o professor continua a formação iniciada nas instituições formadoras de professores. Daí a necessidade de se oportunizar espaços de interação colaborativa para que os professores possam socializar os conhecimentos construídos, identificar os problemas existentes e tentar resolvê-los para melhorar seu fazer pedagógico. Assim, a formação continuada deve estar voltada para o professor em exercício e tem como função básica contribuir para o professor ampliar e alterar de maneira crítica, a própria prática. Como afirma Perrenoud (2002), essa mudança ocorre diante da reflexão sistemática sobre seu próprio fazer pedagógico, para entendê-lo e modificá-lo. Falsarella (2004) compartilha dessa ideia ao afirmar que:

[...] a formação continuada como proposta intencional e planejada, que visa a mudança do educador através de um processo reflexivo, crítico e criativo, conclui-se que deva motivar o professor a ser ativo agente na pesquisa de sua 
própria prática pedagógica, produzindo conhecimento e intervindo na realidade (FALSARELLA, 2004, p. 50).

Ainda de acordo com Ibernón (2002), é necessário que o docente esteja em constante processo de formação, buscando sempre se qualificar, pois com uma formação continuada ele poderá melhorar sua prática docente e seu conhecimento profissional, levando em consideração a sua trajetória pessoal, pois a trajetória profissional do educador só terá sentido se relacionada a sua vida pessoal, individual e na interação com o coletivo. Ele deve se formar com a capacidade de refletir sobre sua prática educacional para se adaptar as diversas e rápidas mudanças no campo educacional, enfrentando assim as dificuldades encontradas na realidade da sala de aula. O professor deve assumir o papel de facilitador e de mediador do conhecimento, um participante ativo da aprendizagem dos alunos, proporcionando uma aprendizagem em que o aluno seja sujeito do processo de ensino e aprendizagem. Agindo como mediador, o docente está dando a oportunidade aos alunos de terem autonomia na construção do seu próprio conhecimento como forma de compreender a realidade social em que vivem.

Nóvoa (2002) defende que o professor precisa ter consciência do seu papel social para que possa ajudar o aluno a compreender a sociedade em que está inserido e a complexidade do conhecimento que se pretende adquirir, tendo como meta principal uma aprendizagem voltada para resolver os problemas que a vida nesta sociedade irá apresentá-lo, dando uma visão crítico/reflexiva das coisas que se apresentarão ao longo da vida. Com isso ele terá a possibilidade de compreender e interpretar os problemas que emergem no cotidiano.

Libâneo (2001, p.189) diz que "a formação continuada é o prolongamento da formação inicial visando o aperfeiçoamento profissional teórico e prático no próprio contexto de trabalho e, ao desenvolvimento de uma cultura geral mais ampla, para além do exercício profissional". O mesmo autor reforça que, para os professores: 
A formação continuada é condição para a aprendizagem permanente e $o$ desenvolvimento pessoal, cultural e profissional. É na escola, no contexto de trabalho, que os professores enfrentam e resolvem problemas, elaboram e modificam procedimentos, criam e recriam estratégias de trabalho e, com isso, vão promovendo mudanças profissionais e pessoais (LIBÂNEO, 2001, p. 151).

Ponte (1998) ressalta que para o professor exercer adequadamente sua atividade profissional ao ensinar Matemática, ele deve:

Ter bons conhecimentos e uma boa relação com a Matemática; conhecer em profundidade o currículo e ser capaz de recriá-lo de acordo com a sua situação de trabalho; conhecer o aluno e a aprendizagem; dominar os processos de instrução, os diversos métodos e técnicas, relacionando-os com os objetivos e conteúdos curriculares; conhecer bem o seu contexto de trabalho, nomeadamente a escola e o sistema educativo; conhecer-se a si mesmo como profissional (PONTE, 1998, p. 30).

Nesse sentido, pensou-se numa formação continuada de professores de Matemática que buscasse respostas aos desafios decorrentes das novas relações entre sociedade e educação, uma vez que a realidade atual exige profissionais preparados, adequadamente, para atender às exigências dos avanços da ciência e tecnologia, que redimensionam as articulações sociais entre os atores, sendo a escola a instituição responsável em preparar os profissionais que atuam nessa sociedade.

\section{A Resolução de Problemas Matemáticos}

Os sistemas nacionais de avaliação da educação básica, como a Prova Brasil, o Exame Nacional para Certificação de Competências de Jovens e Adultos - Encceja e o Exame Nacional do Ensino Médio - Enem, junto com os sistemas de avaliação internacional, como o Programme for International Student Assessment - Pisa, cada vez mais têm exigido dos alunos a competência para resolução de problemas, e não somente em Matemática.

O Enem, por exemplo, traz em sua matriz de referência, no eixo cognitivo, comum a todas as áreas de conhecimento, que o aluno deve enfrentar situaçõesproblema, ou seja, selecionar, organizar, relacionar, interpretar dados e informações 
representadas de diferentes formas, para tomar decisões e enfrentar situaçõesproblema.

De acordo com Brasil (2008), as matrizes de referência que norteiam a Prova Brasil estão estruturadas sobre o foco da resolução de problemas. Essa opção traz implícita a convicção de que o conhecimento matemático ganha significado quando os alunos têm situações desafiadoras para resolver e trabalham para desenvolver estratégias de resolução.

Conforme os Parâmetros Curriculares Nacionais - PCN (BRASIL, 1998), um dos objetivos do Ensino Fundamental é que os alunos sejam capazes de questionar a realidade formulando-se problemas e tratando de resolvê-los, utilizando para isso o pensamento lógico, a criatividade, a intuição, a capacidade de análise crítica, selecionando procedimentos e verificando sua adequação.

A resolução de problemas, como eixo organizador do processo de ensino e aprendizagem de Matemática, pode ser resumida nos seguintes princípios, de acordo com os PCN (BRASIL, 1998):

No processo de ensino e aprendizagem, conceitos, ideias e métodos matemáticos devem ser abordados mediante a exploração de problemas, ou seja, de situações em que os alunos precisem desenvolver algum tipo de estratégia para resolvê-las. Só há problema se o aluno for levado a interpretar o enunciado da questão que lhe é posta e a estruturar a situação que lhe é apresentada; aproximações sucessivas de um conceito são construídas para resolver certo tipo de problema; num outro momento, o aluno utiliza o que aprendeu para resolver outros, o que exige transferências, retificações, rupturas, segundo um processo análogo ao que se pode observar na História da Matemática; um conceito matemático se constrói articulado com outros conceitos, por meio de uma série de retificações e generalizações. Assim, pode-se afirmar que o aluno constrói um campo de conceitos que toma sentido num campo de problemas, e não um conceito isolado em resposta a um problema particular; a resolução de problemas não é uma atividade para ser desenvolvida em paralelo ou como aplicação da aprendizagem, mas uma orientação para a aprendizagem, pois proporciona o contexto em que se podem apreender conceitos, procedimentos e atitudes matemáticas (BRASIL, 1998, p. 40-41). 
Ainda de acordo com os PCN (1998), um problema matemático é uma situação que demanda a realização de uma sequência de ações ou operações para obter um resultado. Ou seja, a solução não está disponível de início, mas é possível construí-la. Em muitos casos, os problemas usualmente apresentados aos alunos não constituem verdadeiros problemas, porque não existe um real desafio nem a necessidade de verificação para validar o processo de solução. O que é problema para um aluno pode não ser para outro, em função dos conhecimentos de que dispõe. Resolver um problema pressupõe que o aluno: "elabore um ou vários procedimentos de resolução (como realizar simulações, fazer tentativas, formular hipóteses); compare seus resultados com os de outros alunos; valide seus procedimentos" (BRASIL, 1998, p. 41).

O fato de o aluno ser estimulado a questionar sua própria resposta, a questionar o problema, a transformar um dado problema numa fonte de novos problemas, a formular problemas a partir de determinadas informações, a analisar problemas abertos (que admitem diferentes respostas em função de certas condições), evidencia uma concepção de ensino e aprendizagem não pela mera reprodução de conhecimentos, mas pela via da ação refletida que constrói conhecimentos (BRASIL, 1998).

Conforme Schoenfeld (1985), a resolução de problemas, na perspectiva indicada pelos educadores matemáticos, possibilita aos alunos mobilizar conhecimentos e desenvolver a capacidade para gerenciar as informações que estão em seu alcance. Assim, os alunos terão oportunidade de ampliar seus conhecimentos acerca de conceitos e procedimentos matemáticos bem como de ampliar a visão que têm dos problemas, da Matemática, do mundo em geral e desenvolver sua autoconfiança.

Dante (2000) assinala o trabalho com resolução de problemas matemáticos como a principal forma de se alcançar os objetivos da Matemática em sala de aula, entre eles, o de fazer o aluno pensar produtivamente. $\mathrm{O}$ autor destaca ainda: 
É necessário formar cidadãos matematicamente alfabetizados, que saibam como resolver, de modo inteligente, seus problemas de comércio, economia, administração, engenharia, medicina, previsão do tempo e outros da vida diária. E, para isso, é preciso que a criança tenha, em seu currículo de Matemática elementar, a resolução de problemas como parte substancial, para que desenvolva desde cedo sua capacidade de enfrentar situaçõesproblema (DANTE, 2000, p. 15).

Ainda, segundo Dante (2000), é possível por meio da resolução de problemas desenvolver no aluno iniciativa, espírito explorador, criatividade, independência e a habilidade de elaborar um raciocínio lógico e fazer uso inteligente e eficaz dos recursos disponíveis, para que ele possa propor boas soluções às questões que surgem em seu dia a dia, na escola ou fora dela.

Dante (2000) sugere que devemos propor aos alunos várias estratégias de resolução de problemas, mostrando-Ihes que não existe uma única estratégia, ideal e infalível. Cada problema exige uma determinada estratégia. A resolução de problemas não deve se constituir em experiências repetitivas, através da aplicação dos mesmos problemas (com outros números) resolvidos pelas mesmas estratégias. O interessante é resolver diferentes problemas com uma mesma estratégia e aplicar diferentes estratégias para resolver um mesmo problema. Isso facilitará a ação futura dos alunos diante de um problema novo. Dessa forma, em sala de aula o professor pode trabalhar com as tentativas e os erros dos alunos, observando o caminho usado para chegar à solução do problema. Essa observação servirá para compreender o raciocínio dos educandos e preparar as discussões em torno da resolução desses problemas, com o intuito de conceber processos de resolução diferentes dos já aprendidos.

Segundo Polya (1978), um grande matemático e pesquisador do tema, o professor que deseja desenvolver nos alunos o espírito solucionador e a capacidade de resolver problemas deve incutir em suas mentes algum interesse por problemas e proporcionar-lhes oportunidades de imitar e de praticar. Além disso, quando o professor resolve um problema em aula, deve dramatizar um pouco as suas ideias e 
fazer a si próprio as mesmas indagações que utiliza para ajudar os alunos. Por meio desta orientação, o aluno acabará por descobrir o uso correto das indagações e sugestões e, ao fazê-lo, adquirirá algo mais importante do que o simples conhecimento de um fato matemático qualquer.

Para se resolver e encaminhar a solução de um problema, segundo Polya (1978), quatro etapas principais podem ser empregadas: compreensão do problema, construção de uma estratégia de resolução, execução de uma estratégia escolhida e revisão da solução, conforme mostrado na Figura 1:

Figura 1: Etapas da resolução de um problema. Fonte: Polya 1978.

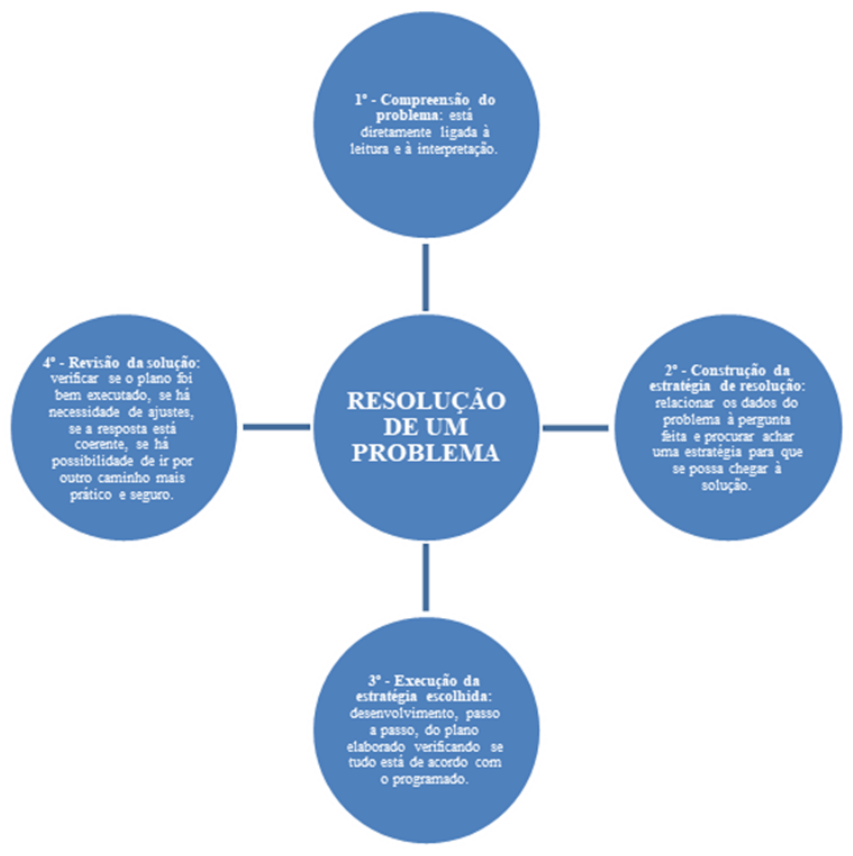

A partir destas etapas, o papel do professor no processo de resolução de problemas consiste em apoiar os alunos, com vista ao desenvolvimento progressivo da autonomia destes e à construção da competência de resolver problemas; colocar-se no lugar do aluno, perceber o ponto de vista deste, procurar compreender o que se passa na sua cabeça; questionar os alunos e fornecer-lhes sugestões, indicando a direção geral para que o mesmo resolva o problema (POLYA, 1978). 
No contexto apresentado, a abordagem da Matemática através da resolução de problemas pode contribuir na formação de cidadãos mais autônomos e críticos, à medida que o aluno se torna agente de sua própria aprendizagem, criando seus métodos e estratégias de resolução, em contrapartida a metodologias mais tradicionais, onde predomina a memorização e mecanização.

Na sociedade atual, onde a demanda por trabalhadores mais críticos, autônomos e criativos é crescente, a Matemática pode dar sua contribuição, à medida que se utilizem "metodologias que enfatizem a construção de estratégias, a comprovação e justificativa de resultados, a criatividade, a iniciativa pessoal, o trabalho coletivo e a autonomia advinda da confiança na própria capacidade de enfrentar desafios" (BRASIL, 1998, p. 27).

Quando o professor adota a metodologia da resolução de problemas, seu papel será de incentivador, facilitador, mediador das ideias apresentadas pelos alunos, de modo que estas sejam produtivas, levando os alunos a pensarem e a gerarem seus próprios conhecimentos. Deve criar um ambiente de cooperação, de busca, de exploração e descoberta, deixando claro que o mais importante é o processo e não o tempo gasto para resolvê-lo ou a resposta final. Sendo assim, o professor deve propor situações-problema que possibilitem a produção do conhecimento, onde o aluno deve participar ativamente compartilhando resultados, analisando reflexões e respostas, enfim aprendendo a aprender.

\section{A Resolução de Problemas na Formação Continuada de Professores de MATEMÁTICA}

De acordo com a Lei Federal 11.892, de 29/12/2008, que cria os Institutos Federais, entre seus objetivos está ministrar cursos de formação inicial e continuada de trabalhadores, objetivando a capacitação, o aperfeiçoamento, a especialização e a atualização de profissionais, em todos os níveis de escolaridade, nas áreas da educação 
profissional e tecnológica. É nesse sentido que as atividades de extensão podem abrir os caminhos de acesso dos diversos públicos às ofertas educativas e oportunidades de formação continuada, contribuindo para democratização institucional. Igualmente, é pela relação dialógica instituição/comunidade, essencial às atividades de extensão, que se descortinam os referenciais de seleção dos conteúdos e componentes curriculares que poderão contribuir para um ensino contextualizado e significativo e para definição de objetos de pesquisa sintonizados com as demandas sociais locais.

Neste sentido, diante das orientações propostas nos documentos legais que norteiam a Educação Básica e das competências exigidas nos sistemas de avaliação nacional e internacional (PROVA BRASIL, ENCCEJA, ENEM e PISA), questionou-se como podemos melhor desenvolver a competência para resolução de problemas com alunos de escolas públicas da Educação Básica. Por isso, pensou-se em desenvolver um projeto com foco na resolução de problemas matemáticos na formação continuada de professores da Educação Básica, por meio de dois cursos de extensão gratuitos, com 40 horas cada, um abordando conhecimentos matemáticos desenvolvidos nos anos finais do Ensino Fundamental e o outro, conhecimentos matemáticos abordados no Ensino Médio.

A formação continuada foi realizada num campus do IFSul, tendo a participação de 15 professores dos anos finais do Ensino Fundamental e de 09 professores do Ensino Médio². Os 10 encontros de cada curso aconteceram quinzenalmente, em terças-feiras, no horário das $18 \mathrm{~h} 30 \mathrm{~min}$ às $22 \mathrm{~h} 30 \mathrm{~min}$, no período de maio a outubro de 2015. Foi desenvolvida pelo professor autor do projeto, licenciado em Matemática, especialista em Pedagogia Gestora, Mestre em Ensino de Ciências e Matemática e

\footnotetext{
${ }^{2}$ Embora se tenha oferecido 20 vagas em cada curso e feita a divulgação da proposta para professores estaduais e municipais da região do Vale do Taquari/RS por diferentes meios de comunicação, houve a inscrição de 27 professores de Matemática em exercício para um total de 40 vagas oferecidas (3 professores não concluíram a formação continuada e 8 professores participaram dos dois cursos).
} 
Doutor em Ensino de Ciências e Matemática, com 15 anos de experiência docente em diferentes níveis de ensino.

Os professores cursistas tinham como perfil: 16 do sexo feminino e 08 do sexo masculino; 12 com vínculo empregatício efetivo e 12 temporários. A experiência profissional docente é representada no Quadro 1:

Quadro 1: Experiência docente. Fonte: Dados dos professores cursistas.

\begin{tabular}{|c|c|c|c|c|}
\hline \multirow{2}{*}{ Tempo de docência } & \multicolumn{2}{|c|}{ Professores do Ensino Fundamental } & \multicolumn{2}{c|}{ Professores do Ensino Médio } \\
\cline { 2 - 5 } & $\mathrm{FA}^{3}$ & $\mathrm{FR}^{4}$ & $\mathrm{FA}$ & $\mathrm{FR}$ \\
\hline Até 5 anos & 07 & 46,66 & 05 & 55,56 \\
\hline De 5 a 10 anos & 04 & 26,67 & 03 & 33,33 \\
\hline Acima de 10 anos & 04 & 26,67 & 01 & 11,11 \\
\hline Total & 15 & 100 & 09 & 100 \\
\hline
\end{tabular}

A partir dos dados apresentados no Quadro 1, aponta-se que a maioria dos cursistas possui menos de 10 anos de experiência docente. Embora a experiência profissional fosse recente, observou-se que os professores participaram ativamente das atividades, compartilhando experiências e dificuldades com o grupo, favorecendo o ressignificado de conceitos matemáticos e da metodologia de resolução de problemas de forma colaborativa, conforme Candau (1996), Falsarella (2004) e Perrenoud (2002).

A formação inicial dos 24 professores cursistas é apresentada no Quadro 2:

Quadro 2: Formação inicial dos professores. Fonte: Dados dos professores cursistas.

\begin{tabular}{|c|c|c|c|c|}
\hline \multirow{2}{*}{ Formação inicial } & \multicolumn{2}{|c|}{ Professores do EF } & \multicolumn{2}{c|}{ Professores do EM } \\
\cline { 2 - 5 } & FA & FR & FA & FR \\
\hline Licenciatura em Ciências Físicas e & & & & \\
Biológicas. & 01 & 6,67 & - & - \\
\hline Licenciatura em Ciências Exatas. & 08 & 53,33 & 05 & 55,56 \\
\hline Licenciatura em Matemática. & $06(02$ em curso) & 40 & 04 (02 em curso) & 44,44 \\
\hline Total & 15 & 100 & 09 & 100 \\
\hline
\end{tabular}

\footnotetext{
3 Frequência absoluta.
}

4 Frequência relativa (\%). 
De acordo com o Quadro 2, observa-se que a maioria dos professores cursistas já concluíram a licenciatura (quatro estão em fase final do curso de Licenciatura em Matemática na modalidade de Educação a Distância - EaD), sendo que apenas uma professora não possui habilitação plena em Matemática. Ressalta-se que predomina a licenciatura em Ciências Exatas, a qual habilita para o ensino de Física, Química e Matemática.

A metodologia do curso de formação continuada se constituiu na investigação sobre o recurso didático da resolução de problemas, fundamentando-se em documentos legais e autores citados na seção 3 deste artigo, e no desenvolvimento de ações didáticas reflexivas, articulando-se a teoria com a prática na resolução de problemas matemáticos. Ressalta-se que, observado o conhecimento incorreto de conceitos matemáticos pelos professores cursistas, desde os primeiros encontros de cada formação, ao propor a resolução de problemas da Olimpíada Brasileira de Matemática das Escolas Públicas - OBMEP e do ENEM, foi necessário replanejar a proposta inicial do projeto, para possibilitar a ressignificação de conhecimentos matemáticos.

\section{A Resolução de Problemas na FormaÇÃo de Professores de MatemÁtica DOS ANOS FINAIS DO ENSINO FUNDAMENTAL}

Após a resolução e discussão de problemas da OBMEP, no curso de extensão "Resolução de Problemas Matemáticos na Formação Continuada de Professores dos Anos Finais do Ensino Fundamental de Escolas Públicas do Vale do Taquari" foram propostas atividades para discussão de conhecimentos matemáticos relacionados à aritmética e à geometria, numa abordagem didática de conceitos matemáticos. Inicialmente, os professores fizeram a discussão dessas atividades em grupos e posteriormente, as ideias foram socializadas no coletivo. Com direcionamento para 
alunos do Ensino Fundamental, algumas atividades propostas estão descritas no

Quadro 3:

Quadro 3: Atividades para abordagem didática de conhecimentos matemáticos. Fonte: Material utilizado no curso de extensão para os anos finais do Ensino Fundamental.

a) Mostre como podemos explicar que "em uma potência cuja base é diferente de zero e o expoente é igual a zero, o resultado é sempre igual a 1 ".

b) Apresente duas maneiras diferentes de se explicar que $\frac{1}{3}+\frac{1}{2}=\frac{5}{6}$.

c) Como podemos explicar que "a multiplicação de um número negativo por outro número negativo, resulta sempre em um número positivo"?

d) Através de dois exemplos, um com base positiva e outro com base negativa, mostre como podemos desenvolver a ideia de "potências com expoente negativo".

e) Descreva uma atividade concreta para determinar o valor aproximado do número $\pi$.

f) Descreva duas maneiras de mostrar que "a soma dos ângulos internos de um triângulo é $1800^{\prime \prime}$

g) Descreva como podemos generalizar que "a soma dos ângulos internos de um polígono de n lados é dada por $\mathrm{Si}=(\mathrm{n}-2) \cdot 1800^{\prime \prime}$

h) Como podemos mostrar que "em um polígono de n lados, o número de diagonais (d) que partem de um único vértice é dado por $d=n-3$ "?

i) Explique como podemos mostrar que "em um polígono de $\mathrm{n}$ lados, o número de diagonais (D) é dado por $D=\frac{n \cdot(n-3)}{2}$ ".

j) Como podemos mostrar que "a área de um paralelogramo é obtida pela multiplicação das medidas de sua base e de sua altura"?

k) Como podemos mostrar que "calculamos a área de um trapézio dividindo por dois o produto de sua altura pela soma das medidas de suas bases"?

I) Explique como podemos mostrar que "calculamos a área de um losango dividindo por dois o produto de suas diagonais".

m) A partir da expressão da área de um triângulo, $A=\frac{b \cdot h}{2}$, mostre como podemos obter a expressão para cálculo da área de um triângulo equilátero de lado $\ell$.

n) Apresente uma demonstração do Teorema de Pitágoras.

O desenvolvimento desta proposta surgiu a partir da necessidade de ressignificação de conhecimentos matemáticos pelos professores, priorizando-se conhecimentos de geometria, a pedido dos cursistas. As discussões coletivas foram significativas na formação, pois permitiram a abordagem de conceitos matemáticos de forma reflexiva e a troca de experiências pedagógicas, o que é defendido por Candau (1996), Falsarella (2004), Ibernón (2002) e Perrenoud (2002). 
Além da resolução de problemas, explorou-se a criação de problemas pelos professores, seguindo-se a proposta apresentada no Quadro 4:

Quadro 4: Proposta para criação de problemas. Fonte: Material utilizado no curso de extensão para os anos finais do Ensino Fundamental.

Em grupos, criar e resolver um problema que envolva:
a) O número 2015.
b) Operações com números positivos e números negativos.
c) Uma equação do 1o grau com uma incógnita.
d) Uma inequação do 10 grau com uma incógnita.
e) Uma equação do 1 o grau com duas incógnitas.
f) Um sistema de duas equações do 1 o grau com duas incógnitas.
g) Uma regra de três simples direta.
h) Uma regra de três simples inversa.

Durante a realização desta atividade se observou que alguns professores apresentaram dificuldades para criar problemas devido à inexperiência com elaboração de problemas e à falta de conhecimentos matemáticos. Depois que os professores criaram e resolveram seus problemas, realizou-se a troca dos mesmos entre os grupos para que os demais professores tomassem conhecimento das ideias dos colegas e também os resolvessem. No Quadro 5 se apresentam algumas situações elaboradas pelos professores:

Quadro 5: Problemas criados pelos professores. Fonte: Professores cursistas.

a) Mamãe e eu compramos uma TV de plasma, no valor de $\mathrm{R} \$ 2015,00$, para dar de presente ao papai. Demos de entrada R\$215,00 e o restante será parcelado em 6 vezes. Quanto pagaremos por mês?

b) Joaquim estava brincando com seu carrinho de controle remoto. Lembrando-se da aula de Matemática, organizou um quadro, onde anotou os metros que o carrinho andava cada vez que ele acionava o controle. Determinou que valores positivos seriam as idas e os negativos as vindas. Ao final, qual era a distância entre Joaquim e o carrinho? O que significa o sinal da resposta que você encontrou?

\begin{tabular}{|c|c|}
\hline Vez & Metros \\
\hline $1^{\circ}$ & +15 \\
\hline $2^{\circ}$ & +3 \\
\hline $3^{\circ}$ & -11 \\
\hline $4^{\circ}$ & +6 \\
\hline $5^{\circ}$ & -18 \\
\hline $6^{\circ}$ & -7 \\
\hline
\end{tabular}


c) Paulo jogando basquete acertou $x$ arremessos de dois pontos, e y arremessos de 3 pontos. Ele acertou no total 25 arremessos e marcou 55 pontos. Quantos arremessos de 3 pontos ele acertou?

d) Um estacionamento está lotado, sendo que há 30 veículos no local, entre carros e motos. Sabendo que ao todo são 104 rodas no chão do estacionamento, quantos são os carros e quantas são as motos no local?

e) Um carro percorre uma distância de 48 km com 3 litros de gasolina. Quantos litros de gasolina serão necessários para percorrer $212 \mathrm{~km}$ ?

f) João irá acampar com cinco amigos. Sua mãe deixou tudo organizado, sendo que comprou comida e bebida para passarem cinco dias acampados. No dia da saída, um domingo, dois primos de João decidiram se juntar a garotada e participar do acampamento. Sendo que não há como comprar mais comida, quantos dias os meninos podem ficar acampados, se a média de comida e bebida calculada pela mãe de João for mantida?

Apesar de serem situações direcionadas para alunos do Ensino Fundamental, observou-se que houve professores com dificuldades na resolução dos problemas, enquanto outros provocaram discussões coletivas devido à linguagem utilizada na sua elaboração, permitindo interpretações variadas. Com a criação de problemas pelos professores, discutiu-se a potencialidade desta atividade e a aplicabilidade da mesma nas aulas de Matemática nos anos finais do Ensino Fundamental, a partir de documentos legais e de autores, como Dante (2000), Polya (1978) e Schoenfeld (1985).

Considerando-se a integralidade da formação continuada dos professores de Matemática dos anos finais do Ensino Fundamental, a prática de resolução de problemas foi relacionada aos seguintes conteúdos: números naturais; frações; números inteiros; proporção; geometria plana; equações do 1o grau com uma incógnita; sistemas de duas equações do 1 o grau com duas incógnitas; expressões algébricas; produtos notáveis e equações do 2ํo grau com uma incógnita. A resolução de problemas aconteceu de forma conjunta à sistematização destes conteúdos com o propósito de ressignificar os conhecimentos matemáticos.

Os cursistas avaliaram a formação continuada de forma positiva, conforme descrito no Quadro 6: 
Quadro 6: Avaliação da formação continuada pelos professores do Ensino Fundamental. Fonte: Professores cursistas.

- "Este curso contribuiu muito para a minha formação devido à troca de experiências com os colegas, as atividades práticas, a socialização das atividades e a revisão de conteúdos que com abordagens diferenciadas se tornam mais atrativas".

- "A abordagem dos conteúdos nos faz refletir e reafirmar aquilo que estamos fazendo corretamente e modificar o que pode estar inadequado. A troca de experiências com colegas também foi muito gratificante. Um curso gratuito e de qualidade".

- "Destaco a troca de experiências, compreensão melhor do desenvolvimento e resolução dos problemas. A formação auxiliou muito com temas que poderei utilizar com meus alunos e com outros casos que já fiz uso do que foi estudado no curso".

- "Os aspectos positivos foram os temas abordados que nos permitiu uma reciclagem da nossa prática pedagógica e revisão de todo o conteúdo do ensino fundamental, onde a troca de conhecimentos foi muito satisfatória. Aprendi várias práticas pedagógicas para trabalhar na sala de aula".

- "Alguns assuntos conseguirei abordar de maneira diferente a partir de agora e penso que essa nova abordagem tornará meu aluno mais reflexivo, contribuindo para a sua aprendizagem".

- "Gostei da troca de experiências com outros professores, da resolução conjunta de problemas, da revisão de conteúdos, das estratégias metodológicas discutidas, dos desafios diferentes e intrigantes, das propostas de atividades criativas, como a caixa de remédios ${ }^{5}$ para explorar expressões algébricas, do banco de questões sobre cada assunto que acabamos formando, o que é muito útil para o professor".

Pelo exposto no Quadro 6, aponta-se que os cursistas destacaram, principalmente, as trocas de experiências com os colegas professores, a discussão coletiva de diferentes metodologias de ensino (resolução de problemas) e a ressignificação de conhecimentos matemáticos desenvolvidos no Ensino Fundamental.

\section{A Resolução de Problemas na FormaçÃo de Professores de Matemática DO ENSINO MÉDIO}

No curso de extensão "Resolução de Problemas Matemáticos na Formação Continuada de Professores do Ensino Médio de Escolas Públicas do Vale do Taquari" foi desenvolvida a prática de resolução de problemas relacionada aos conteúdos de: estatística; matemática financeira; função afim, quadrática, exponencial e logarítmica;

\footnotetext{
5 A partir de caixas de remédios, exploraram-se, algebricamente, o perímetro e a área de superfícies planas (caixa de
} remédios planificada) e a área total e o volume de poliedros. 
progressão aritmética e geométrica; sistemas lineares; análise combinatória; probabilidade; trigonometria; geometria plana e espacial.

Nesta formação, a discussão da resolução de problemas também aconteceu de forma conjunta à sistematização dos conteúdos para que os professores cursistas pudesssem ressignificar os conhecimentos matemáticos. Aponta-se que os professores apresentaram dificuldades para resolver problemas extraídos do ENEM e demonstraram conhecimentos superficiais dos conteúdos desenvolvidos no Ensino Médio.

Pelos relatos dos professores durante a formação, o conteúdo de estatística ainda é pouco explorado nas escolas, limitando-se ao estudo da representação tabular e gráfica de dados. Chamou atenção a falta de conhecimentos sobre as medidas de tendência central e de dispersão pelos professores cursistas. Com relação à matemática financeira, em que se propôs a resolução de problemas envolvendo porcentagem, juros simples e juros compostos, identificaram-se dificuldades dos professores no cálculo da taxa de juros e do tempo, no sistema de juros compostos.

Verificou-se que no estudo das funções a resolução de problemas era mais praticada na abordagem das funções afim e quadrática. O estudo da análise combinatória foi desenvolvido a partir de uma atividade com figuras planas para que os cursistas pudessem ressignificar os conceitos de arranjo e combinação e resolver problemas de análise combinatória com mais segurança.

No estudo da probabilidade também se verificou, terem conhecimentos superficiais, sendo necessária a retomada de conhecimentos de probabilidade para a resolução de problemas. Mesmo sendo necessário replanejar a formação continuada devido ao conhecimento limitado de conteúdos matemáticos do Ensino Médio pelos cursistas, acredita-se que a proposta atingiu seus objetivos. Os professores cursistas 
do Ensino Médio também avaliaram a formação continuada positivamente. No Quadro

7 se apresentam algumas opiniões:

Quadro 7: Avaliação da formação continuada pelos professores do Ensino Médio. Fonte: Professores cursistas.

- "É sempre importante aprimorar nossos conhecimentos. Sempre há algo de novo para aprender. Problemas muito bem elaborados, com situações do cotidiano. Atividades que posso reaproveitar com meus alunos. Momento de troca de experiências. Todos os conteúdos abordados foram muito importantes e significativos, mas agora aprendi com mais segurança os problemas envolvendo logaritmos e funções exponenciais".

- "Estatística foi o conteúdo mais importante para meu aprendizado, porque foi trabalhado de forma contextualizada o que permitiu uma melhor compreensão e uma simplificação deste conteúdo, tão pouco trabalhado".

- "Hoje me sinto mais confiante, pois muito do que estou fazendo em sala de aula está de acordo com o que foi trabalhado. Também serviu para que eu reveja alguns aspectos, corrija-os e melhore o meu trabalho. Destaco o estudo da análise combinatória para interpretação de quando é arranjo ou combinação".

- "Aponto os materiais práticos, concretos, para explicar alguns conteúdos; as atividades debatidas no grupo. Algumas atividades que realizamos em aula já apliquei com meus alunos do Ensino Médio".

- "Possibilitou pensar de maneiras diferentes. Foi estimulada a criação de perguntas aos alunos. A prática feita em análise combinatória foi maravilhosa. Os espaços de discussão eram ótimos, pois discutíamos vários olhares sobre uma mesma questão".

Na avaliação desta formação continuada os professores destacaram as trocas de experiências com os colegas professores, os materiais e propostas de atividades diversificadas e a ressignificação de conhecimentos matemáticos desenvolvidos no Ensino Médio, como por exemplo: função exponencial, logaritmos, estatística e análise combinatória.

A partir das atividades desenvolvidas durante o projeto, apresentam-se considerações finais sobre a resolução de problemas na formação continuada de professores de Matemática da Educação Básica.

\section{CONSIDERAÇÕES FINAIS}

O projeto possibilitou a pesquisa sobre a metodologia de resolução de problemas e o desenvolvimento de ações didáticas reflexivas, articulando-se a teoria 
com a prática na resolução de problemas matemáticos, contribuindo para a ressignificação de conhecimentos matemáticos e da metodologia de resolução de problemas no fazer pedagógico de 24 professores de escolas públicas.

Para o desenvolvimento da metodologia de resolução de problemas foi necessário ressignificar conhecimentos matemáticos desenvolvidos na Educação Básica, pois alguns conceitos matemáticos não eram bem compreendidos pelos professores cursistas ou até mesmo desconhecidos, como: arranjo, combinação, mediana, moda, variância e desvio-padrão.

A discussão coletiva de diferentes formas de resolução de um problema, as trocas de experiências pedagógicas e a ressignificação de conceitos matemáticos desenvolvidos na Educação Básica, foram pontos de destaque do projeto desenvolvido.

Acredita-se que refletindo sobre a resolução de problemas matemáticos no fazer pedagógico de professores de escolas públicas e ressignificando a metodologia de resolução de problemas na construção de conhecimentos matemáticos desenvolvidos na Educação Básica, estar-se-á motivando os docentes para a utilização da metodologia de resolução de problemas nas aulas de Matemática e possibilitando que os mesmos desenvolvam a competência para resolução de problemas nos alunos da Educação Básica.

A partir desta investigação, aponta-se a necessidade de mais programas e projetos de formação continuada para professores de Matemática da Educação Básica, promovidos pelas instituições de Ensino Superior, articulando-se os conhecimentos matemáticos teóricos e práticos com as realidades vivenciadas no âmbito das escolas públicas. 


\section{REFERÊNCIAS}

BRASIL, Lei 11.892/2008. Cria os Institutos Federais. Brasília, 2008.

BRASIL. Ministério da Educação. PDE - Plano de Desenvolvimento da Educação: SAEB: Ensino Médio: matrizes de referência, tópicos e descritores. Brasília: MEC, SEB, Inep, 2008.

BRASIL. Ministério da Educação. Resolução CNE/CP 2/2015. Define as Diretrizes Curriculares Nacionais para a formação inicial em nível superior (cursos de licenciatura, cursos de formação pedagógica para graduados e cursos de segunda licenciatura) e para a formação continuada. Diário Oficial da União, Brasília, DF, 2 jul. 2015. Seção 1, pp. 8-12. Disponível em: <php?option=com_docman\&view=download\&alias=17719res-cne-cp-002-03072015\&category_slug=julho-2015-pdf\&Itemid=30192>. Acesso em: 5 jan. 2016.

BRASIL. Secretaria de Educação Fundamental. Parâmetros Curriculares Nacionais: Matemática. Secretaria de Educação Fundamental. Brasília: MEC/SEF, 1998.

CANDAU, V. M. F. A formação continuada de professores: tendências atuais. In: REALI, Aline de M. R.; MIZUKAMI, M. da G. N. (Orgs.). Formação de professores: tendências atuais: São Carlos: EDUFSCar, 1996. p. 139-152.

DANTE, Luiz Roberto. Didática da resolução de problemas de matemática. 12. ed. São Paulo: Ática, 2000.

FALSARELLA, A. M. Formação continuada e prática de sala de aula: os efeitos da formação continuada na atuação do professor. Campinas, SP: Autores Associados, 2004.

FAUSTINO, Monica Podsclan. Ações de formação continuada de professores que ensinam Matemática nos anos iniciais do Ensino Fundamental da rede municipal de Presidente Prudente (SP) e saberes docentes. 2011. 203 f. Dissertação (Mestrado em Educação) - Universidade Estadual Paulista, UNESP, Presidente Prudente, 2011.

IMBERNÓN, Francisco. Formação docente e profissional: formar-se para mudança e a incerteza. 6. ed. São Paulo: Cortez, 2000.

KUHN, Malcus Cassiano; BAYER, Arno. A formação de professores em tempos de incertezas. ACTA SCIENTIAE. Revista de Ensino de Ciências e Matemática, ULBRA Canoas, v. 15, n. 1, p. 226-236, jan./abr. 2013.

LIBÂANEO, J. C.. Organização e gestão da escola: teoria e prática. Goiânia: Alternativa, 2001.

NóVOA, Antonio. Formação de professores e trabalho pedagógico. Lisboa/Portugal: Educa, 2002. 
PERRENOUD, Philipp. As competências para ensinar no século XXI: a formação dos professores e o desafio da avaliação. Porto Alegre: Artmed, 2002.

POLYA, G. A arte de resolver problemas. Rio de Janeiro: Interciência, 1978.

PONTE, J. P. Da formação ao desenvolvimento profissional. In: Actas do ProfMat 98. Lisboa: APM, 1998, p. 27- 44.

SCHOENFELD, A. H. Mathematical problem solving. Nova York: Academic Press, 1985. 